\title{
A seleção de obras literárias para o Programa Nacional Biblioteca da Escola - PNBE 2006-2014
}

Célia Regina Delácio Fernandes ${ }^{1}$

\section{Introdução}

O Programa Nacional Biblioteca da Escola (PNBE), instituído em 1997 pelo Ministério da Educação (MEC), é objeto deste estudo, ${ }^{2}$ que investiga os critérios que as instâncias governamentais julgaram relevantes na escolha das obras literárias compradas pelo Estado para serem distribuídas nas escolas públicas brasileiras. Com o principal objetivo de promover a leitura para a formação plena do cidadão, o PNBE compreende a literatura como "um patrimônio cultural a que todos os cidadãos devem ter acesso" (Brasil, 2009a, p. 25). Assim, com a finalidade de garantir o acesso à leitura literária e à democratização da cultura na escola, viabilizando a diversidade das fontes de informação, o PNBE funcionou por quase duas décadas, tendo sido suspenso em 2015.

Ao longo dos 18 anos de existência, conforme estudos anteriores realizados com outros recortes temporais (Fernandes, 2007; Fernandes e Cordeiro, 2012), os critérios de avaliação das obras literárias do PNBE, juntamente com o programa, passaram por muitas transformações, aprimorando-se a cada edição. Convém lembrar que, nas primeiras edições do programa, os critérios não foram explicitados. Somente a partir de 2001 esses critérios são estabelecidos em edital, publicado no Diário Oficial da União e colocado à disposição na internet, mas até 2004 percebem-se muitas insuficiências na exposição desses critérios (Fernandes e Cordeiro, 2012).

Neste estudo, a documentação oficial - no caso, os editais - é analisada como um dado fundamental para o entendimento de aspectos do sistema literário no qual circula a literatura infantojuvenil, procurando compreender o que é considerado literatura de boa qualidade nessa instância de legitimação (Bourdieu,

\footnotetext{
${ }^{1}$ Doutora em teoria e história literária e professora da Universidade Federal da Grande Dourados (UFGD), Dourados, MS, Brasil. E-mail: celiafernandes@ufgd.edu.br

${ }^{2}$ Este artigo é resultado parcial de minha pesquisa de pós-doutorado, realizada no Programa de Pósgraduação em Letras da Universidade Estadual de Maringá (UEM), sob a supervisão da profa. dra. Mirian Hisae Yaegashi Zappone.
} 
1996). Sublinha-se que o processo de seleção das obras literárias começa com a elaboração e a publicação do edital pelo MEC, que determina as regras a serem seguidas tanto por aqueles que vão concorrer (as editoras) como para aqueles que vão coordenar a avaliação pedagógica do PNBE (a universidade, a partir de 2005).

No período em questão - 2006 a 2014 -, a seleção das obras de literatura ficou sob a responsabilidade do Centro de Alfabetização, Leitura e Escrita (Ceale), da Faculdade de Educação (FAE), da Universidade Federal de Minas Gerais (UFMG). A coordenação do processo, baseada nas regras e prazos dos editais, encarregou-se de montar a ficha de avaliação, as equipes de pareceristas e o Colegiado. Ao constituir tais equipes, compostas por mestres e doutores de universidades, com múltiplas experiências de docência e atuação na área, a coordenação descentralizou o processo, inserindo avaliadores das mais diferentes localidades. Para a coordenadora do processo de seleção de obras literárias do PNBE de 2006 a 2014, Aparecida Paiva, a tarefa de avaliar obras é bastante complexa, principalmente por causa do desafio maior de saber "se o que está sendo selecionado, como de qualidade, despertará o interesse do jovem leitor" (Paiva, 2012, p. 302).

Ao examinar os editais das edições de 2006 a 2014, com foco no anexo que aborda os critérios de avaliação e seleção, conclui-se que os critérios são sempre três: qualidade de texto, adequação temática e projeto gráfico. No edital do PNBE 2005, havia um quarto critério - o da representatividade (Brasil, 2004, p. 14), mas que desaparece nos editais subsequentes. No conjunto, após cotejar os editais que regulamentaram o processo de avaliação e seleção das oito edições do PNBE, foi possível constatar que ocorreram poucas modificações na redação dos textos. Em alguns momentos, observam-se alterações, principalmente para incluir ou excluir alguns trechos, conforme serão destacados na análise a seguir.

Registra-se que, nesse período, o público-alvo se alterna em cada edição, com o objetivo de atender todos os segmentos do ensino. Desse modo, o PNBE 2006 atende aos alunos dos anos finais do ensino fundamental (EF) enquanto as edições de 2009, 2011 e 2013 beneficiam tanto os alunos dos anos finais do ensino fundamental quanto os do ensino médio (EM). As outras edições, dos anos 2008, 2010, 2012 e 2014, atendem aos estudantes de educação infantil (creche e pré-escola), dos anos iniciais do ensino fundamental e da educação de jovens e adultos. Destaca-se que, a partir de 2008, a educação infantil e o ensino médio 
também são contemplados pelos acervos, ampliando-se a distribuição do PNBE. Embora os públicos atendidos sejam de faixas etárias diferentes, os critérios de seleção dos editais para avaliar se uma obra é boa são os mesmos para todos os segmentos.

\section{O que é qualidade do texto no PNBE?}

Em linhas gerais, os editais apresentam uma explicação introdutória sucinta sobre o critério de qualidade do texto, indicando a contribuição que o texto literário deve proporcionar aos leitores - ampliação do repertório linguístico e fruição estética - e apontando o que será avaliado "as qualidades textuais básicas e o trabalho estético com a linguagem" (Brasil, 2007, p. 15). Excetua-se o edital do PNBE 2009, em que figura "repertório cultural" no lugar de "repertório linguístico" (Brasil, 2008, p. 13). Os editais das edições 2008, 2010, 2012 e 2014, considerando que o público atendido está em fase de alfabetização, acrescentam que os textos serão selecionados "de modo equilibrado, tanto para favorecer uma leitura autônoma pela criança, quanto para estimular uma apropriação dos textos pela leitura do professor em voz alta" (Brasil, 2007, p. 15; 2009a, p. 27; 2010, p. 24; 2012, p. 20). Ou seja, esse trecho abre espaço para escolha de obras que exigem um fôlego maior que o leitor iniciante não tem, mas que podem ser lidas pelo mediador adulto. Na sequência, os editais indicam os pontos a serem avaliados nos textos em prosa e nos textos em verso, a questão ética e o que deve ser evitado, as traduções e adaptações e, por fim, os livros de imagens e as histórias em quadrinhos.

Para os textos em prosa, os editais repetem os mesmos itens de avaliação: "a coerência e a consistência da narrativa, a ambientação, a caracterização das personagens e o cuidado com a correção e a adequação do discurso das personagens a variáveis de natureza situacional e dialetal" (Brasil, 2006, p. 14; 2007, p. 15; 2008, p. 13; 2009 a, p. 27; 2009b, p. 14; 2010, p. 24; 2011, p. 21; 2012, p. 20). No edital do PNBE 2011 consta o acréscimo inicial do item "adequação da linguagem ao público pretendido" (Brasil, 2009b, p. 14) e no edital de 2013 consta o acréscimo no final do texto do item "o desenvolvimento do tema em harmonia com os recursos narrativos" (Brasil, 2011, p. 21). São acréscimos que explicitam o que, de certa forma, já está pressuposto nesse critério. 
No que diz respeito aos textos em verso, em todos os editais, a avaliação está direcionada para "a adequação da linguagem ao público a que se destina e sua coerência tendo em vista os diferentes princípios que, historicamente, vêm orientando a produção e a recepção literária" (Brasil, 2006, p. 14; 2007, p. 15; 2009a, p. 27; 2010, p. 24; 2012, p. 20). Observa-se que os princípios não são explicitados, no entanto, os editais do PNBE 2011 e 2013 acrescentam: "em especial os que se referem aos aspectos melódicos, imagéticos e/ou visuais na produção poética" (Brasil, 2009b, p. 14; 2011, p. 21). Assim, o avaliador precisa compreender os diferentes princípios que estão implícitos na avaliação do texto em verso, sendo que alguns desses aspectos foram mencionados e priorizados apenas em editais posteriores.

Entre os elementos a serem avaliados nos gêneros literários, há uma normatização de que os textos devem ser "eticamente adequados" e evitar "preconceitos, moralismos, estereótipos". É compreensível que, em se tratando de compras realizadas com dinheiro público, seja obrigatório impedir textos inadequados do ponto de vista ético. Mas e os outros elementos? É possível o texto literário se apresentar isento daquilo que está presente no mundo da vida? O texto literário consegue, de fato, não reproduzir os padrões de exclusão da sociedade brasileira?

Como se tratam de critérios excludentes, os editais deveriam explicitar melhor o que estão entendendo por cada um desses elementos. O edital do PNBE 2013 altera o texto para: “Não serão selecionadas obras que apresentem clichês ou estereótipos saturados" (Brasil, 2011, p. 21). Essa formulação melhora ou complica mais o problema, tendo em vista que o edital não conceitua esses termos? Podem-se, portanto, aceitar estereótipos não saturados? Para contribuir com essa discussão, Cosson e Paiva (2014) chamam a atenção para a lógica que precinge esse item, ao refletirem sobre essa problemática de um ponto de vista teórico e prático, revelando a complexidade da questão:

Em um entendimento teórico, trata-se de selecionar obras que se apresentem como originais ou, pelo menos, que contribuam para uma nova forma de ver e dizer o mundo. Na prática, entretanto, a questão é mais delicada. Há que se considerar, por exemplo, que o clichê e o estereótipo não podem ser dissociados dos estilos de época, dos gêneros e da história do leitor. Uma obra que simplesmente reproduz os elementos estilísticos do Romantismo nos dias atuais pode ser vista como clichê, mas um texto daquele 
período com os mesmos elementos não. Obras de um gênero fortemente marcado, como a fábula ou o romance policial, podem parecer estereotipados por apresentar estrutura e personagens similares. Para o leitor que nunca leu um texto daquele estilo ou gênero, os clichês e os estereótipos podem passar despercebidos. Além do mais, a repetição ou a previsibilidade de certos textos são relevantes para os leitores infantis ou neoleitores jovens e adultos, que são parte do público a quem se destinam os acervos do PNBE. Percebe-se, com isso, que a lógica da qualidade literária não pode ser pensada apenas em relação a elementos textuais, recursos expressivos e trabalho estético com a linguagem, mas também com base em elementos intertextuais e contextuais que constituem o texto enquanto obra literária (Cosson e Paiva, 2014, p. 493).

Para ilustrar a dificuldade dessa isenção de discriminação e estereótipo na obra literária, registre-se a polêmica infindável sobre o suposto racismo na obra Caçadas de Pedrinho, de Monteiro Lobato, escolhida para os acervos do PNBE de 1998 e 2003, que circulou amplamente na mídia com argumentos pró e contra a suspensão da distribuição desse livro nas escolas. Tal polêmica sobre os termos racistas no livro iniciou-se em 2010, quando a seleção dessa obra retorna a cena a partir da denúncia do gestor educacional Antônio Gomes da Costa Neto, com a determinação do Conselho Nacional de Educação (CNE) em vetar o livro. Esse episódio provocou inúmeras manifestações, seguidas das intervenções do MEC e anulação do veto, com a recomendação da nota técnica para orientar o professor sobre o conteúdo racista no contexto histórico de produção da obra. O impasse com um escritor canônico, da envergadura de Lobato, considerado o criador da literatura infantil no Brasil, é modelar para exemplificar a problemática em pauta.

Na continuação do critério de qualidade, o texto prescreve sobre as adaptações e traduções. Nos editais 2006 e 2008, apesar de o público-alvo ser distinto, mencionam-se as "adaptações e traduções". Essa dupla de palavras continua a constar nos editais de 2010, 2012 e 2014, destinados ao público dos anos iniciais do ensino fundamental, porém, nos editais de 2009, 2011 e 2013, figura apenas a palavra "traduções". Por que as adaptações desaparecem desses editais? Seria por causa de o ensino médio vir a fazer parte do edital junto com os anos finais do EF? Nesse caso, as séries finais do EF ficariam privadas de adaptações? No que diz respeito ao texto explicativo desse critério, o edital do PNBE 2006 traz 
uma explanação que considera "os aspectos textuais e editoriais", o endereçamento e os paratextos, além de confirmar as qualidades literárias da obra original (Brasil, 2006, p. 14). Na edição sequente, no PNBE 2008, o texto é sintetizado em: "No caso das adaptações e traduções, é importante que sejam mantidas as qualidades literárias da obra original" (Brasil, 2007, p. 15). Nessa exigência apresenta-se uma complicação, pois se torna necessário que o avaliador tenha conhecimento da obra original - e da língua em que foi escrita - para fazer a comparação com a obra adaptada ou traduzida. Nas edições seguintes, o texto é mantido, variando apenas em "é importante que sejam mantidas" para traduções (Brasil, 2008, p. 13) e "devem ser mantidas" (Brasil, 2009a, p. 27) quando aparecem traduções e adaptações, o que leva a inferir que há uma preocupação maior com as adaptações em detrimento das traduções. E o que seria manter "as qualidades literárias da obra original", concebendo tanto a tradução e a adaptação como reescrituras com potenciais para gerar outras qualidades literárias? Essas obras também não seriam originais com novas qualidades textuais e editoriais? Na contemporaneidade, inclusive, são questionados os limites em que essas reescrituras se inscrevem e a ausência de fronteiras que delimite objetivamente essas noções.

Por último, no critério qualidade, o texto normatiza sobre os livros de imagens e as histórias em quadrinhos. Registre-se que, no edital do PNBE 2006, com público-alvo exclusivo das séries finais do ensino fundamental, os dois gêneros são previstos: “Nos livros de imagens e quadrinhos será considerado como critério preponderante a relação texto-imagem e as possibilidades de leitura das narrativas pictóricas" (Brasil, 2006, p. 14). Contudo, a partir do edital do PNBE 2009, é inserido o segmento do ensino médio, que continua junto com os anos finais do ensino fundamental nos editais das edições 2011 e 2013. Observa-se no edital do PNBE 2009 a eliminação dos livros de imagens da composição dos acervos para esse público-alvo: o item 4.2.6. do edital menciona apenas histórias em quadrinhos (Brasil, 2008, p. 2). Paradoxalmente, no entanto, os livros de imagens fazem parte do item "caracterização dos acervos" nos editais de 2011 - "3.5.6. livros de imagens e livros de histórias em quadrinhos" (Brasil, 2009b, p. 2) - e de 2013 - "3.6.6. livros de imagens e livros de histórias em quadrinhos" (Brasil, 2011, p. 2). A despeito disso, no critério sobre a qualidade de textos das edições 2011 e 2013, não consta a expressão "livros de imagens": "No caso das histórias em quadrinhos será considerado como critério preponderante a relação entre texto e 
imagem e as possibilidades de leitura das narrativas visuais" (Brasil, 2009 b, p. 14; 2011, p. 21). Teria sido descuido de quem elaborou tais editais incluir o gênero "livro de imagens" na composição dos acervos e fazê-lo desaparecer da parte referente aos critérios?

No que diz respeito aos critérios do PNBE para avaliar as histórias em quadrinhos, Vergueiro e Ramos (2015, p. 36) advogam a necessidade de "que existam critérios mais específicos e menos genéricos". Segundo esses especialistas, da maneira como esses critérios foram escritos, "sinalizam características próprias à composição das histórias em quadrinhos". Assim, concluem que: "Todas aquelas que foram inscritas no programa estariam, em tese, por esses critérios, aptas a serem selecionadas. Subentende-se, então, que a decisão final de seleção fica refém de elementos subjetivos" (Vergueiro e Ramos, 2015, p. 36). Com isso, os autores marcam a posição de que os quadrinhos precisam ser avaliados como uma linguagem ou uma manifestação artística autônoma, por seu próprio conteúdo, e não como gênero literário. Ou seja, na visão desses estudiosos "quadrinhos são quadrinhos e literatura é literatura" (Vergueiro e Ramos, 2015, p. 36).

Nessa direção, então, poder-se-ia indagar se livro de imagem é literatura, considerando literatura como a arte da palavra e que o livro de imagem não tem texto escrito e conta a narrativa somente com ilustrações, aproximando-se mais da linguagem das artes visuais. Para conceituação, Luís Camargo (1995, p. 70), em livro pioneiro sobre o assunto, defende o uso da expressão "livro de imagens" para "livros em que a história é contada unicamente por imagens", ou seja, para as narrativas que dispensam o uso de palavras. Nesse sentido, onde estaria a literariedade do texto no livro de imagem? Nas figuras de linguagem visual, que podem ou não estar presentes nas ilustrações (Camargo, 1995, p. 108)? Ou na concepção de ilustração como um tipo de texto, um "texto visual", em que a imagem pode desempenhar as mesmas funções da linguagem verbal e incluir outras, como propõe Camargo (2003, p. 274-279)? Para dialogar com esse aspecto e complicar ainda mais a questão: como analisar a relação entre texto e imagem em um gênero que não faz uso da palavra escrita? Tais indagações colocam um problema ainda maior: é possível considerar livro de imagens e histórias em quadrinhos como gêneros literários? O edital do PNBE, com essas inserções, estaria alargando o conceito de literatura? 
Como se vê, o critério de qualidade do texto provoca reflexões e desafios. Além de toda controvérsia em torno do livro de imagem e de histórias em quadrinhos serem ou não literatura, pode-se problematizar sobre outros gêneros presentes nos editais, tais como: "parlendas, cantigas, travalínguas, adivinhas", "texto da tradição popular"; "biografias", "ensaio", "relatos de experiências" etc. Sem a pretensão de responder a esses questionamentos, mas apontar para a polêmica que envolve o conceito de literatura e, principalmente, a Literatura (com L maiúsculo) considerada de boa qualidade, chancelada pelas instâncias de legitimação conforme já analisado por especialistas da área (Abreu, 2006; Culler, 1999; Lajolo, 2001; Zappone e Wielewicki, 2003). No caso do PNBE, o problema da avaliação fica ainda maior, porque se trata de escolher obras literárias com qualidade para circular nas escolas públicas de todo o Brasil. Para colaborar com esse debate, a coordenadora do processo de seleção, verbaliza sua "maior inquietação" sobre a avaliação do texto literário:

Nossa maior inquietação é a possível distância entre a composição dos acervos e a apropriação efetiva dos mesmos pelos jovens. A angústia de quem avalia, se podemos colocar a questão nesses termos, é se o que é selecionado despertará o interesse do jovem leitor. $\mathrm{O}$ avaliador nunca tem certeza se o endereçamento está adequado: o avaliador analisa os acervos, os gêneros e as temáticas que o compõem e não pode afirmar categoricamente que essa é a única forma de composição; não é raro também que outros professores pesquisadores manifestem sua discordância (o acervo poderia ser composto com outras obras) ou críticas (o endereçamento foi subestimado ou superestimado), ou seja, as possibilidades são várias e não há como negar esse fato (Paiva, 2012, p. 302).

Com essa inquietação, é importante debruçar-se sobre o próximo critério do edital para compreender o que se considera no critério de adequação temática.

\section{O que se considera no critério de adequação temática?}

O edital coloca em relevo a diversidade temática e seus diferentes contextos sociais, culturais e históricos para contemplar a multiplicidade que compõe a sociedade brasileira. Nos editais 2010, 2012 e 2014, foram acrescentados os contextos "socioeconômicos" e "ambientais", ampliando 
o panorama a ser abarcado nas obras. Observa-se o cuidado de compor um acervo com temas diversificados, com representações de vários contextos, adequados aos interesses dos numerosos leitores, e de acordo com o segmento destinado. Com efeito, ao lado dessa variação temática, considera-se o endereçamento da obra a ser selecionada, que deve estar adequada às expectativas e aos interesses do público-alvo. Destaca-se que o edital de 2009 acrescenta "a linguagem" ao lado da "temática", aumentando as exigências: "A linguagem e a temática dessas obras deverão estar adequadas à faixa etária e aos interesses dos alunos do ensino fundamental e do ensino médio" (Brasil, 2008, p. 13). Nos próximos editais, no entanto, a linguagem não volta a figurar.

De modo geral, os editais 2006 a 2014 mencionam algumas características para avaliação das obras literárias focadas no endereçamento: "a capacidade de motivar a leitura", "o potencial para incitar novas leituras", "a adequação às expectativas do público-alvo", "as possibilidades de ampliação das referências do universo dos diferentes públicos" e "a exploração artística dos temas". Todavia, considerando as dimensões do país e a diversidade do público-alvo atendido pelo PNBE, como lidar com a multiplicidade de tantos universos, referências e interesses? Esse público-alvo, previsto em cada edital, conseguirá nortear a escolha do avaliador, correspondendo às expectativas do leitor endereçado, de carne e osso? O edital 2009 acrescenta "as possibilidades de ampliação do repertório dos jovens para além do que já conhecem e o desenvolvimento da percepção estética dos leitores" (Brasil, 2008, p. 14). Como se vê, as características elencadas pressupõem um trabalho artístico com os temas variados para ampliação das referências estéticas e culturais do leitor pretendido.

Ressalte-se que o edital fala da composição dos acervos de forma a assegurar ao leitor um panorama representativo não apenas da literatura brasileira, mas também da estrangeira. É possível compor um panorama tão amplo nesse processo de seleção de obras? Cosson e Paiva (2014, p. 493-494), fundamentados nos editais do PNBE 2012 e 2013, respondem afirmativamente, justificando a presença da lógica da diversidade das obras que abrangeria quatro critérios vinculados à formação do leitor: "diversidade temática", "diversidade de representação", "diversidade de formas e gêneros" e a "diversidade de níveis de complexidade de elaboração das obras". Em vista dessa argumentação, que considera a diversidade no conjunto das lógicas, 
Cosson e Paiva (2014, p. 494) concluem que "o efeito que daí resulta é um acervo constituído por uma ampla variedade de obras", e arrematam: "o conceito de literatura do PNBE é de inclusão".

Com certeza, tanto os avaliadores quanto o Colegiado que participam do processo de seleção procuram zelar por uma composição plural do acervo e atender às exigências do edital. A despeito disso, pode-se argumentar que o processo de avaliação resta condicionado à escolha das obras literárias inscritas pelas editoras, cuja produção subordina-se aos interesses do mercado. Em outras palavras, antes mesmo de o avaliador escolher as obras, as obras já foram escolhidas pelas editoras.

Nessa perspectiva, a dissertação de Venâncio (2009) investiga a presença de características que valorizam a diversidade nos personagens apresentados pelas obras que compõem o acervo do PNBE 2008, apontando para a ausência de estudos que aprofundem a discussão sobre os critérios de seleção das obras e do uso dos acervos nas escolas, e afirmando que quem define os temas e as imagens é a indústria cultural:

Fica, portanto, a critério da indústria cultural a definição dos temas mais pertinentes voltados ao público infantil e juvenil, bem como a escolha das imagens a serem vinculadas à palavra escrita, num processo que pode tanto contemplar a diversidade quanto desmerecê-la ao enfocar atributos tidos como mais conformes a uma ordem social na qual a diferença é motivo de estranhamento (Venâncio, 2009, p. 51).

Por essa razão, a autora propõe a criação de "critérios qualitativos de análise da produção, difusão e acessibilidade da obra literária" (Venâncio, 2009 , p. 52) que possibilitem rever o ensino da literatura infantojuvenil, bem como romper com os processos de padronização e estigmatização dos personagens e das ilustrações. O resultado da pesquisa de Venâncio (2009, p. 160) mostra a "quase ausência de personagens deficientes e a pouca representatividade do negro e do indígena" nos livros do PNBE 2008, convergindo com os estudos realizados pela pesquisadora Regina Dalcastagnè (2005), que analisou 1.245 personagens de 285 romances brasileiros contemporâneos, publicados entre os anos de 1990 e 2004.

Essa pesquisa de Dalcastagnè (2005) tem contribuído e dialogado com outros estudos sobre diversidade e representações na literatura infantojuvenil brasileira, porque propicia comparar os dados levantados e confirmar a exclusão de determinados grupos sociais e de diversas vozes e perspectivas, negando as diferenças e as desigualdades na produção 
literária destinada a crianças e jovens. De acordo com a pesquisadora, a desvalorização na caracterização ou a ausência de determinados grupos sociais na literatura brasileira, especialmente dos pobres e negros, reproduz o silêncio e a invisibilidade desses grupos na sociedade brasileira. Tal conclusão é extremamente importante para se pensar a questão da diversidade na composição dos acervos do PNBE.

Decerto os acervos observam temáticas variadas e são compostos de maneira plural sob alguns aspectos, no entanto, conceituar a diversidade e explicitá-la como critério de seleção ainda é um desafio para o edital do PNBE. Algumas pesquisas têm se debruçado sobre as obras literárias selecionadas para examinar o requisito da diversidade, apontando limitações na composição dos acervos do PNBE (Kaercher, 2005; Ferreira, 2008; Venâncio, 2009; Oliveira, 2010; Silveira e Bonin, 2012; Lopes, 2012; Araujo, 2015; Zappone, 2015; Fernandes e Paula, 2015; Paula e Fernandes, 2016).

Em linhas gerais, ao investigarem as dificuldades ou os silêncios sobre as temáticas da "diversidade", esses estudos evidenciam a necessidade de a seleção do PNBE contemplar mais temas sobre diversidade étnico-racial, outras representações sociais e geográficas dos espaços das histórias, outros grupos sociais e padrões de personagens não hegemônicos (homens, brancos, heterossexuais, de classe média e sem deficiência).

Nessa direção, os estudos realizados sobre os acervos apontam para a urgência de o PNBE apresentar uma formulação propositiva e incisiva sobre o critério da diversidade para fomentar uma produção literária enriquecida com uma multiplicidade de vozes, que seja capaz de reconhecer outros grupos sociais e mostrar representações de outros personagens heterogêneos. Não se trata da produção literária promover o politicamente correto, com discursos panfletários e doutrinadores, mas uma obra literária plural, que aborde o tema com qualidades estéticas e capacidade de romper criticamente com estereótipos e preconceitos, contestando a "invisibilização" e o "silenciamento" dos grupos marginalizados que, segundo a pesquisadora Dalcastagnè (2005, p. 22), indicam o caráter excludente tanto do campo literário quanto da sociedade brasileira.

Por fim, em todos os editais expõem-se, por meio de uma redação expressa em termos imprecisos, alguns critérios eliminatórios, pois normatizam para não selecionar "obras que apresentem didatismos, moralismos, preconceitos, estereótipos ou discriminação de qualquer 
ordem." O edital do PNBE 2013 repete o mesmo texto, mas se diferencia dos outros por adicionar outro trecho que, embora redundante, especifica outros elementos excludentes: “Da mesma forma, não serão selecionadas obras que apresentem didatismos, que contenham teor doutrinário, panfletário ou religioso" (Brasil, 2011, p. 22). Estudos sobre a questão étnico-racial propõem que essa formulação genérica do edital do PNBE seja substituída por outra de caráter propositivo, a exemplo do que ocorre com o edital do PNLD, que incluiu a diversidade como critério de seleção, especificando de maneira clara a valorização dos diferentes segmentos étnico-raciais da sociedade brasileira (Venâncio, 2009, p. 101; Oliveira, 2010, p. 90). Em outros termos, registra-se que o edital do PNBE fala em diversidade temática como critério, no entanto, não coloca como critério de seleção retratar, por exemplo, as diferenças étnicas e raciais, de gênero, de idade ou relativas a deficientes.

\section{Quais são as exigências para o projeto gráfico?}

Ao cotejar os oito editais, observa-se que o projeto gráfico e o editorial são vistos e avaliados no conjunto, como aspectos que compõem o objeto livro. Na lista desses aspectos, no que diz respeito à adequação e à expressividade - apesar de várias alterações sobre as especificações dos itens em cada edição do edital -, percebe-se que eles permanecem: "capa, uso de tipos gráficos, espaçamento e distribuição textual, equilíbrio na distribuição do texto e das imagens e na distribuição do texto e informações complementares, funcionalidade do sumário, dos prefácios, das notas" (Brasil, 2006, p. 15).

No caso da capa, por exemplo, o edital 2006 menciona apenas a palavra "capa", o edital 2008 descreve "apresentação de capa criativa e atraente" (Brasil, 2007, p. 15); o edital 2009 esclarece "apresentação de capa apropriada ao projeto estético-literário da obra" (Brasil, 2008, p. 14); enquanto o edital 2010 pormenoriza: "apresentação de capa criativa e atraente, apropriada ao projeto estético-literário da obra" (Brasil, 2009a, p. 28). Há uma melhora gradativa na especificação desse item, no entanto, nos editais de 2011 e 2013, esse texto desaparece, retornando nos editais das edições de 2012 e 2014. Se, por um lado, essas alterações indicam um aprimoramento do texto no sentido de tornar mais claro o objeto da avaliação e sua significância nas obras destinadas aos leitores iniciantes; por outro lado, a retirada da "capa" como item específico de avaliação nas 
edições de 2011 e 2013 parece sinalizar que esse aspecto tem menos importância quando se trata de selecionar obras voltadas para os alunos matriculados nos anos finais do ensino fundamental e no ensino médio. Nesse sentido, o edital enfraquece a avaliação da capa numa formulação subentendida e comete um equívoco, porque, independentemente da faixa etária, ela pode ser o elemento mais importante para atrair ou afastar o leitor do objeto livro. A esse respeito, Cosson (2012, p. 310) pondera sobre a relação de coerência entre a capa e o conteúdo do livro, exemplificando com as obras clássicas, que atinge o público jovem:

Há que se observar, na dimensão material, a relação de coerência entre a capa e o conteúdo do livro, assim como a adequação entre ilustração e texto verbal. Normalmente, são as obras clássicas as maiores vítimas do desencontro entre capa e conteúdo do livro. $\mathrm{Na}$ tentativa de atrair o leitor, o projeto gráfico termina emprestando excessiva modernidade à capa, contrariando o interior do livro. O inverso também acontece, ou seja, livros com capas excessivamente sóbrias, sem nenhum convite à curiosidade do leitor, apesar de trazerem histórias para lá de divertidas. Nos dois casos, as capas não funcionam como portas de entrada para a obra. Ao contrário, são elementos do projeto gráfico-editorial que distanciam o leitor ou conduzem a uma escolha equivocada quanto ao tipo de livro que ele desejaria ler.

Além da capa, outros elementos previstos nos editais podem favorecer ou não a leitura do livro, tais como os tipos de letras, o espaço entre as linhas, distribuição do texto e das imagens. $\mathrm{O}$ avaliador precisa estar atento a essas características, porque a leitura exige esforço, e a legibilidade visual do texto facilita sua compreensão. Sabe-se que determinados tipos e tamanhos de letras, espaço pequeno entre as linhas, falta de contraste entre a impressão da letra e o fundo da página, a distribuição irregular da mancha gráfica na página, a má qualidade do papel, entre outros exemplos, podem afastar o público pretendido da leitura. E, para além dos aspectos visuais, os paratextos (prefácio, apresentação, posfácio, notas, orelha, quarta capa, dados biográficos dos autores etc.) podem proporcionar a contextualização da obra, colaborando para seu entendimento. Acerca disso, observam-se alterações menos relevantes nos editais com o objetivo de sintetizar a redação, mas alargando a abrangência do objeto. Por exemplo, o trecho "informações complementares, funcionalidade do sumário, dos prefácios, das notas" do 
edital do PNBE 2006 (Brasil, 2006, p.15) é substituído nos editais seguintes por "pertinência das informações complementares" (Brasil, 2007, p. 15; 2008, p. 14; 2009a, p. 28; 2010, p. 24; 2012, p. 21), com exceção das edições do PNBE 2011 e 2013. Como o edital do PNBE 2008 também atende aos alunos da educação infantil e dos anos iniciais do EF, ele acrescenta os aspectos relevantes para esse público: "ilustrações que interagem com o texto, artisticamente elaboradas; uso de papel adequado à leitura e ao manuseio pelas crianças" (Brasil, 2007, p. 15). Tais aspectos se mantêm nos editais subsequentes para esse segmento. Mais um pormenor acrescido, a partir do edital do PNBE 2008, foi a exigência acerca do modo de apresentação dos dados biográficos dos autores:

A biografia do(s) autor(es) deverá ser apresentada de forma a enriquecer o projeto gráfico e promover a contextualização do autor e da obra no universo literário. Igualmente, outras informações devem ter por objetivo a ampliação das possibilidades de leitura, em uma linguagem acessível à criança (Brasil, 2007, p. 15).

Como se vê, os paratextos assumem importância na avaliação do projeto gráfico, contribuindo para qualificar a obra com sua contextualização e revelar sua adequação para seu destinatário. $\mathrm{O}$ trecho citado acima passa a constar nos editais subsequentes, alterando a especificação do público (criança, jovem, adulto e idoso) e acrescentando "informações relevantes e consistentes" (Brasil, 2008, p. 14). Outra adição considerável é feita no edital do PNBE 2010: "quando couber, com informações a respeito das técnicas utilizadas para elaboração das ilustrações" (Brasil, 2009a, p. 28).

Outras informações que fazem parte do critério do projeto gráfico e perpassam todos os editais são as seguintes: a qualidade das ilustrações e das imagens e os elementos que prejudicam a avaliação da obra. Com relação às imagens e às ilustrações, o aspecto mais significativo, sem dúvida, é a relação dialógica que devem estabelecer com o texto. O edital do PNBE 2008 avança ao afirmar a obrigatoriedade do diálogo entre imagem e texto, e adiciona a ampliação de suas significações: "Elas devem dialogar com o texto, ampliando suas possibilidades significativas" (Brasil, 2007, p. 15). O edital do PNBE 2010, no entanto, melhora a formulação ao agregar outros valores, conseguindo incluir a diversidade de linguagens e ampliar os sentidos a serem atribuídos aos textos: "Quanto às ilustrações e imagens, devem recorrer a diferentes linguagens, ser atrativas e enriquecedoras, ampliando as possibilidades significativas dos textos" 
(Brasil, 2009a, p. 28). A despeito desse avanço, ressalta-se o fato de que os editais das edições 2011 e 2013 não incorporaram esse trecho, o que leva a concluir que quanto maior o nível de escolarização, menos importância assume a ilustração. Pode-se supor que não se trate somente de faixa etária, mas do grau de escolaridade, porque os editais em que há um desaparecimento da ilustração em detrimento da complexidade dos textos atendem a alunos das séries finais do ensino fundamental e médio, enquanto os outros atendem às crianças e aos adultos e idosos do ensino de jovens e adultos (EJA) de nível fundamental e médio: "O projeto gráficoeditorial deve apresentar equilíbrio entre texto principal, ilustrações, textos complementares e as várias intervenções gráficas que conduzem o leitor para dentro e para fora do texto principal" (Brasil, 2009b, p. 15; 2011, p. 22).

Registre-se que não há em nenhum dos editais uma explicitação do que venha a ser essa relação dialógica entre o texto e a imagem. Como a imagem e o texto dialogam e ampliam as possibilidades de leitura? Ao mapear informações sobre esse aspecto, foi possível encontrar algumas explicações na exposição do instrumento de avaliação construído, nas categorias de análise elaboradas por Andrade e Corsino (2007), como critérios para seleção de obras literárias para os anos iniciais do ensino fundamental do PNBE 2005. Nessa edição, os critérios são estruturados em quatro categorias abrangentes: elaboração da linguagem literária, pertinência temática, ilustração e projeto gráfico-editorial. Nota-se que a ilustração é analisada como critério separado do projeto gráfico-editorial, apontando para os seguintes esclarecimentos:

Quanto à ilustração, foi observada a relação estabelecida entre o aspecto visual e o texto verbal: o diálogo entre o verbal e o não verbal, também foi visto na sua dimensão polifônica. Uma ilustração que retrate literalmente o que o verbal expressa não estabelece uma leitura dialógica do texto literário, já uma ilustração que busque atravessar o verbal em sua referencialidade e estabelecer a partir dele uma leitura própria, propositiva e criativa, pôde ser considerada uma boa ilustração. Os avaliadores buscaram identificar se o universo de significação era afetado pela imagem, se as imagens marcavam uma plurissignificação, pelo tratamento estético visual que traziam para o texto verbal (Andrade e Corsino, 2007, p. 86-87).

Também para atender aos critérios dispostos no edital de cada edição sob a responsabilidade do Ceale, Paiva $(2012$, p. 304) informa que a equipe da coordenação produziu uma ficha com vários itens para 
avaliação das obras inscritas no PNBE. O texto traz uma descrição bem geral dessa ficha e inclui, nos "detalhes quanto ao projeto gráfico", o quesito "a relação texto-imagem a qualidade das interações quando presentes no livro" (Paiva, 2012, p. 304). Trata-se apenas de uma menção a esse item, que é abordado com mais detalhamento na explanação de Cosson (2012, p. 310):

Já a relação entre as ilustrações e o texto verbal é um tanto mais complexa e demanda maior cuidado no trabalho de avaliação, porque faz parte de um todo, que é a obra. Texto visual e texto verbal interagem entre si, principalmente em obras infantis e histórias em quadrinhos, não podendo simplesmente um ser reduzido a outro. Em outras palavras, livros com ilustrações exigem uma dupla, ainda que interdependente, leitura: uma da palavra e outra da imagem. Por isso, esses dois registros textuais precisam dialogar coerentemente entre si na unidade que constitui a obra. Ilustrações que apenas repetem especularmente o que está dito no texto verbal são pobres e quase nada contribuem para a leitura da obra. Ilustrações que nada dizem sobre o texto verbal são obscuras e tampouco auxiliam o processo de interpretação da obra.

Para finalizar o critério do projeto gráfico, uma ressalva digna de nota em todos os editais é o comprometimento da avaliação quando a obra apresentar erros de revisão e/ou de impressão. Como se trata de um objeto para circular em ambientes escolares, é inadmissível a apresentação de erros considerados crassos, mas o texto que coloca isso como exclusão, de maneira clara, consta apenas no edital do PNBE 2013: "Não serão selecionadas obras que apresentem erros crassos de revisão e/ou impressão" (Brasil, 2011, p. 22). Esse quesito impõe ao mercado editorial um cuidado primoroso com a revisão dos textos, aperfeiçoando a qualidade dos textos a serem avaliados.

Como se vê, a qualidade do projeto gráfico é analisada em relação a todos esses aspectos que, além de produzir visibilidade e legibilidade, dialogam com a proposta estética e literária da obra, ampliando sentidos e agregando valores. No mundo contemporâneo, não se pode negar a relevância desse critério para a seleção do PNBE. Em seus estudos sobre a história cultural, Chartier (1990; 2002) tem apontado para a necessidade de considerar a materialidade do livro (capa, ilustrações, cores, formato, papel, distribuição das ilustrações e do texto, 
tamanho e tipo de letra etc.) nas investigações sobre o livro e a leitura, ponderando que os aspectos materiais influenciam nas práticas de leitura e interferem na interpretação do texto pelo leitor.

Segundo Chartier (2002, p. 62), as várias formas materiais do livro são responsáveis por sua leitura, pois fazem parte da construção de significados do livro, influenciando sua recepção. Assim, o critério do projeto gráfico é fundamental para avaliação de um livro, porque, na contemporaneidade, os aspectos visuais do objeto livro tornam-se imprescindíveis para instigar a leitura do texto literário.

Para a história cultural (Chartier, 1990, p. 16-17), o livro não é um objeto neutro, mas vinculado às práticas sociais de determinada sociedade, portanto, as palavras e as imagens trazem representações do mundo social, traduzindo suas perspectivas e seus interesses a serem apreendidos pelos leitores. Em vista disso, os aspectos gráficos mereciam uma formulação mais precisa no edital do PNBE, detalhando melhor os itens a serem avaliados, principalmente em relação às ilustrações.

Outra sugestão que poderia ser incorporada na redação do texto do edital é a valorização da diversidade nas imagens, ou seja, para além de não apresentar imagens preconceituosas e estereotipadas, o edital poderia fomentar de maneira incisiva a criação de textos visuais que apresentem representações da diversidade étnica, cultural e social.

\section{Considerações finais}

De modo geral, é possível perceber vários aspectos favoráveis presentes nos critérios de seleção dos editais, ainda que se possa problematizar uma melhor especificação dos termos abordados ou dos quesitos a serem avaliados. Além da preocupação com a qualidade do texto, acompanhada da diversidade temática, cultural e estética, sempre articuladas com o endereçamento adequado, também se destaca a atenção com a materialidade da obra expressa na avaliação do projeto gráfico.

Outra questão digna de nota presente em todos os editais é o cuidado em selecionar obras que não contenham "preconceitos, estereótipos ou discriminação de qualquer ordem", que pode ser compreendido com o dever do Estado com a formação ética do leitor e do cidadão, com o princípio constitucional da igualdade e do respeito pela alteridade nas relações humanas. Ao lado disso, excluem-se também os didatismos ou moralismos, impedindo que sejam 
selecionadas obras de natureza predominantemente didáticas, que se utilizam do texto literário como pretexto para transmitir, de maneira explícita, conteúdos instrutivos ou morais com a intenção de ensinar. Assim, a concepção de literatura no edital procura se desvincular do "compromisso pedagógico" que acompanha essa produção literária desde sua origem, tornando-se "instrumento para inculcação de normas e valores" (Fernandes, 2007, p. 2). Nessa perspectiva, Fernandes e Cordeiro (2012, p. 324) afirmam que essa instrumentalização continua ocorrendo e que o edital propõe uma ruptura com essa descaracterização do texto literário.

Com efeito, os editais também revelaram avanços em outras dimensões: no atendimento de todos os segmentos de ensino e também dos alunos com necessidades especiais (obras disponibilizadas em braille e em CD de áudio); na diversidade de gêneros, temas, formas e linguagens; na inclusão de uma introdução nos critérios para falar da importância da leitura; no impedimento da inscrição de títulos que foram selecionados em edições anteriores do PNBE; na limitação da quantidade de obras por editora, a partir do edital do PNBE 2010, entre outros.

$\mathrm{O}$ resultado mais significativo deste estudo é evidenciar que o processo de seleção do PNBE consegue ampliar o conceito de literatura. Ao lado do livro de imagem e das histórias em quadrinhos, a ampliação do conceito de literatura no edital também pode ser percebida com a inclusão de textos que são considerados menores (ou não considerados) pela crítica elitista, como as adaptações, os textos da tradição oral (lendas, mitos, adivinhas, parlendas etc.), as biografias e os relatos de experiências, não se circunscrevendo às obras canônicas, mas constituindo acervos bem representativos (Cosson, 2012, p. 311-313).

Como aspectos desfavoráveis, ao longo do artigo, foram apontados alguns trechos, termos e expressões que precisam ser aprimorados ou esclarecidos nos requisitos do edital. Também é preciso que o edital fomente uma produção literária nacional mais plural, que rompa com o silêncio imposto pelas classes dominantes ao longo de séculos. Essa democratização da representação dos grupos sociais, espaços geográficos e culturais é fundamental para transformar as relações de poder tanto no campo literário quanto na sociedade brasileira.

Como se trata de uma política pública estatal de incentivo à leitura, torna-se necessário que o edital explicite a definição da palavra "diversidade", para possibilitar a construção de identidades e 
realidades diferentes e incorporar de forma inequívoca a contemplação de temas pertencentes à diversidade étnica, racial, econômica, sexual e social. A proposta é enriquecer o conteúdo verbal e visual dessa produção para crianças e jovens, com a representação de grupos heterogêneos, sem perder de vista a qualidade literária e suas características artísticas, mas ampliando as referências estéticas, sociais e culturais do leitor pretendido. Nesse prisma, espera-se que essa política pública possa favorecer a representação dos diferentes grupos que constituem a sociedade brasileira na produção literária a ser comprada e distribuída nas escolas, contribuindo para a emancipação do leitor em formação e para promover uma valorização da diferença nas relações humanas. Somado a isso, nota-se uma lacuna de critérios que possam favorecer a produção literária regional e nacional, conforme assinalado por Cosson e Paiva (2014, p. 482).

Para concluir, apesar de o PNBE ter se instituído como uma política de Estado ao longo de sua trajetória, ele foi suspenso em 2015 e até o momento não há informações sobre sua continuidade. Pela importância que representa o acesso à leitura literária de qualidade e à democratização da cultura, este artigo aponta as deficiências do PNBE visando sua melhoria, e defende sua continuidade para efetivar o direito à literatura, patrimônio cultural, que o Estado tem o dever de garantir para todos os cidadãos.

\section{Referências}

ABREU, Márcia (2006). Cultura letrada: literatura e leitura. São Paulo: Editora da Unesp. ANDRADE, Ludmila; CORSINO, Patrícia (2007). Critérios para a constituição de um acervo literário para as séries iniciais do ensino fundamental: o instrumento de avaliação do PNBE 2005. In: PAIVA, Aparecida et al. (Org.). Literatura: saberes em movimento. Belo Horizonte: Ceale; Autêntica, p.79-91.

ARAUJO, Debora Cristina de (2015). Literatura infanto-juvenil e política educacional: estratégias de racialização no Programa Nacional de Biblioteca da Escola (PNBE). Tese (Doutorado em Educação) - Universidade Federal do Paraná, Curitiba.

BOURDIEU, Pierre (1996). As regras da arte: gênese e estrutura do campo literário. Tradução de Maria Lúcia Machado. São Paulo: Cia. das Letras.

BRASIL (2004). Ministério da Educação. Fundo Nacional de Desenvolvimento da Educação. Edital de convocação para inscrição de obras de literatura no processo de 
avaliação e seleção para o Programa Nacional Biblioteca da Escola - PNBE/2005. Brasília. Disponível em: https://goo.gl/sOM2Gc. Acesso em: 13 out. 2015.

BRASIL (2006). Ministério da Educação. Fundo Nacional de Desenvolvimento da Educação. Edital de convocação para inscrição de obras de literatura a serem distribuídas às escolas públicas do ensino fundamental, no processo de avaliação $e$ seleção para o Programa Nacional Biblioteca da Escola - PNBE/2006. Brasília. Disponível em: https://goo.gl/1yBSjy. Acesso em: 13 out. 2015.

BRASIL (2007). Ministério da Educação. Fundo Nacional de Desenvolvimento da Educação. Edital de convocação para inscrição de obras de literatura no processo de avaliação e seleção para o Programa Nacional Biblioteca da Escola - PNBE 2008. Brasília. Disponível em: https://goo.gl/ol5IG2. Acesso em: 13 out. 2015.

BRASIL (2008). Ministério da Educação. Fundo Nacional de Desenvolvimento da Educação. Edital de convocação para inscrição de obras de literatura no processo de avaliação e seleção para o Programa Nacional Biblioteca da Escola - PNBE 2009. Brasília. Disponível em: https://goo.gl/Rpn5Km. Acesso em: 13 out. 2015.

BRASIL (2009a). Ministério da Educação. Fundo Nacional de Desenvolvimento da Educação. Edital de convocação para o processo de inscrição e avaliação de obras de literatura para o Programa Nacional Biblioteca da Escola - PNBE 2010. Brasília. Disponível em: https://goo.gl/uUOjP4. Acesso em: 13 out. 2015.

BRASIL (2009b). Ministério da Educação. Fundo Nacional de Desenvolvimento da Educação. Edital de convocação para o processo de inscrição e avaliação de obras de literatura para o Programa Nacional Biblioteca da Escola - PNBE 2011. Brasília. Disponível em: https://goo.gl/GnrFEF. Acesso em: 13 out. 2015.

BRASIL (2010). Ministério da Educação. Fundo Nacional de Desenvolvimento da Educação. Edital de convocação para o processo de inscrição e avaliação de obras de literatura para o Programa Nacional Biblioteca da Escola - PNBE 2012. Brasília. Disponível em: https://goo.gl/hvVIcN. Acesso em: 13 out. 2015.

BRASIL (2011). Ministério da Educação. Fundo Nacional de Desenvolvimento da Educação. Edital de convocação para inscrição e seleção de obras de literatura para o Programa Nacional Biblioteca da Escola - PNBE 2013. Brasília. Disponível em: https://goo.gl/egtuJ3. Acesso em: 13 out. 2015.

BRASIL (2012). Ministério da Educação. Fundo Nacional de Desenvolvimento da Educação. Edital de convocação para inscrição e seleção de obras de literatura para o Programa Nacional Biblioteca da Escola - PNBE 2014. Brasília. Disponível em: https://goo.gl/jZvgw2. Acesso em: 13 out. 2015.

CAMARGO, Luís (1995). Ilustração do livro infantil. Belo Horizonte, MG: Lê. 
CAMARGO, Luís (2003). Para que serve um livro com ilustrações? In: JACOBY, Sissa (Org.). A criança e a produção cultural: do brinquedo à literatura. Porto Alegre: Mercado Aberto, p. 273-301.

CHARTIER, Roger (1990). A história cultural entre práticas e representações. Lisboa: Difel; Rio de Janeiro: Bertrand.

CHARTIER, Roger (2002). Os desafios da escrita. São Paulo: Editora da Unesp.

COSSON, Rildo (2012). Avaliação pedagógica de obras literárias. Educação, Porto Alegre, v. 35, n. 3, p. 308-318, set./dez.

COSSON, Rildo; PAIVA, Aparecida (2014). O PNBE, a literatura e o endereçamento escolar. Remate de Males, Campinas, v. 34, n. 2, p. 477-499, jul./dez.

CULLER, Jonathan (1999). Teoria literária: uma introdução. Tradução de Sandra Vasconcelos. São Paulo: Beca.

DALCASTAGNÈ, Regina (2005). A personagem do romance contemporâneo: 1990 2004. Estudos de Literatura Brasileira Contemporânea, Brasília, n. 26, p. 13-71, jul./dez.

FERNANDES, Célia Regina Delácio (2007). Leitura, literatura infanto-juvenil e educação. Londrina: Eduel.

FERNANDES, Célia Regina Delácio; CORDEIRO, Maisa Barbosa da Silva (2012). Os critérios de avaliação e seleção do PNBE: um estudo diacrônico. Educação, Porto Alegre, v. 35, n. 3, p. 319-328, set./dez.

FERNANDES, Célia Regina Delácio; PAULA, Flávia Ferreira. (2015). Literatura, infância e o projeto "Literatura em Minha Casa". Revista Teias, Rio de Janeiro, v. 16, n. 41, p. 72-88, abr./jun.

FERREIRA, Leda Cláudia da Silva (2008). A personagem do conto infanto-juvenil brasileiro contemporâneo: uma análise a partir de obras do PNBE/2005. Dissertação (Mestrado em Literatura) - Universidade de Brasília, Brasília.

KAERCHER, Gládis Elise Pereira da Silva (2005). O mundo na caixa: gênero e raça no Programa Nacional de Biblioteca da Escola - 1999. Tese (Doutorado em Educação) - Universidade Federal do Rio Grande do Sul, Porto Alegre.

LAJOLO, Marisa (2001). Literatura: leitores e leitura. São Paulo: Moderna.

LOPES, Naiane Rufino (2012). Programa Nacional Biblioteca da Escola (PNBE) 2010: personagens negros como protagonistas e a construção da identidade étnico-racial. Dissertação (Mestrado em Educação) - Universidade Estadual Paulista "Júlio de Mesquita Filho", Marília.

OLIVEIRA, Veridiane Cintia de Souza (2010). Educação das relações étnico-raciais e estratégias ideológicas no acervo do PNBE 2008 para educação infantil. Dissertação 
(Mestrado em Educação) - Universidade Federal do Paraná, Curitiba. Disponível em: https://goo.gl/Lw4unN. Acesso em: 10/03/2016.

PAIVA, Aparecida (2012). Selecionar é preciso, avaliar é fundamental: acervos de literatura para jovens leitores. Educação, Porto Alegre, v. 35, n. 3, p. 301-307, set./dez.

PAULA, Flávia Ferreira; FERNANDES, Célia Regina Delácio (2016). Pluralidade cultural na literatura infantojuvenil brasileira: Projeto Literatura em Minha Casa em questão. Acta Scientiarum: Language and Culture, Maringá, v. 38, n. 3, p. 233-241, jul./set.

SILVEIRA, Rosa Maria Hessel; BONIN, Iara Tatiana (2012). A temática indígena em livros selecionados pelo PNBE: análises e reflexões. Educação, Porto Alegre, v. 35, n. 3, p. 329-339, set./dez.

VENÂNCIO, Ana Carolina Lopes (2009). Literatura infanto-juvenil e diversidade. Dissertação (Mestrado em Educação) - Universidade Federal do Paraná, Curitiba.

VERGUEIRO, Waldomiro; RAMOS, Paulo (2015). Os quadrinhos (oficialmente) na escola: dos PCN ao PNBE. In: VERGUEIRO, Waldomiro; RAMOS, Paulo. Quadrinhos na educação: da rejeição à prática. São Paulo: Contexto, p. 9-42.

ZAPPONE, Mirian Hisae Yaegashi (2015). Narrativa juvenil brasileira no acervo PNBE 2013: faces urbanas da representação social. Revista Teias, Rio de Janeiro, v. 16, n. 41 , p. $89-107$, abr./jun.

ZAPPONE, Mirian Hisae Yaegashi; WIELEWICKI, Vera Helena Gomes (2003). Afinal, o que é literatura? In: BONNICI, Thomas; ZOLIN, Lúcia Osana (Org.). Teoria literária: abordagens históricas e tendências contemporâneas. Maringá: Eduem, p. 19-32.

Recebido em 9 de novembro de 2016.

Aprovado em 5 de março de 2017.

\section{resumo/abstract/resumen}

\section{A seleção de obras literárias para o Programa Nacional Biblioteca da Escola - PNBE 2006-2014}

Célia Regina Delácio Fernandes

Este artigo objetiva analisar os critérios de seleção para a constituição dos acervos de livros literários enviados às escolas públicas brasileiras pelo Programa Nacional Biblioteca da Escola, em suas edições de 2006 a 2014, que teve o 
Ceale/UFMG como órgão responsável pela avaliação pedagógica das obras de literatura. Para tanto, recorre às fontes documentais, especialmente os editais produzidos pelo Ministério da Educação para esse período. Assim, além de contribuir para o debate sobre o que é considerado literatura de boa qualidade, este estudo se justifica pela defesa da continuidade e do aprimoramento do PNBE como uma importante política pública de leitura. De modo geral, os resultados apontam para uma ampliação no conceito de literatura, mas também para a necessidade de especificações de alguns aspectos da avaliação e para a valorização de temas sobre a diversidade étnica, racial, econômica, sexual e social nos editais, fomentando uma produção literária mais plural.

Palavras-chave: critérios de seleção, literatura infanto-juvenil, políticas públicas de leitura, editais do PNBE.

\section{The selection of literary books for the Programa Nacional Biblioteca da Escola - PNBE 2006-2014}

Célia Regina Delácio Fernandes

This article aims to analyze the selection criteria for the constitution of collections of literary books sent to Brazilian public schools by the "Programa Nacional Biblioteca da Escola" [National School Library Program], between 2006 to 2014. During this time period, Ceale/UFMG were the institutions responsible for the pedagogical evaluation of literary books. The study uses documentary sources, especially the Ministry of Education's public notions during this period. Thus, in addition to contributing to the debate about what is considered "good" literature, this study makes a case for the continuation and enhancement of PNBE as an important public reading policy. The study's results point to an expansion of the concept of literature, but also to the need for clearer assessment tools for the program, as well as the need to promote ethnic, racial, economic, sexual and social diversity, thereby encouraging a more plural literary production.

Keywords: selection criteria, children's literature, public policies on reading, PNBE public announcements.

\section{La selección de obras literárias para el Programa Nacional Biblioteca de la Escuela - PNBE 2006-2014}

\section{Célia Regina Delácio Fernandes}

El presente artículo objetiva analizar los criterios de selección para la constitución de las colecciones de libros literarios enviados a las escuelas públicas brasileñas por el Programa Nacional Biblioteca de la Escuela en sus 
ediciones 2006-2014, que tenían Ceale / UFMG como el organismo encargado de la evaluación pedagógica de las obras literarias. Por lo tanto, utiliza fuentes documentales, especialmente las licitaciones realizadas por el Ministerio de la Educación para ese período. Además de contribuir al debate sobre lo que se considera la literatura de buena calidad, este estudio se justifica por la defensa de la continuidad y mejora del PNBE como una importante política de lectura pública. En general, los resultados apuntan a una expansión en el concepto de la literatura, pero también a la necesidad de especificar algunos aspectos de las cuestiones de evaluación y a la valoración de temas sobre la diversidad étnica, racial, económica, sexual y social en las licitaciones, promoviendo una producción literaria más plural.

Palabras clave: criterios de selección, literatura infantil y juvenil, políticas públicas de lectura, licitaciones del PNBE. 